\title{
Research on the Ancient-Costume Film Role Shaping Based on the Perspective of Costume Pattern Design
}

\author{
Wang Zheng \\ Jiangsu Open University, Nanjing 210013, Jiangsu, China
}

Keywords: Costume pattern; Ancient costume film; Role shaping; Function

\begin{abstract}
At present, world-renowned film awards such as Oscar Golden Statuettes have set up the costume design awards, especially, Hong Kong Film Awards has set up the "best costume pattern award", which fully explains the important position of costume pattern design in film art, and embodies the concern and attention of the world filmdom on costume pattern design. Based on the living examples of ancient costume films, this paper analyzes the basic functions of characters' role shaping in costume pattern design, and puts forward the concepts and methods of costume pattern design required by ancient-costume film role shaping. The objective of this paper is to provide reference for costume pattern design of China's ancient costume films, and design more excellent costume patterns, thus satisfying the function needs of ancient-costume films and further carrying forward the culture and spirit of Chinese folk costume.
\end{abstract}

\section{Introduction}

At present, superb costume pattern has become a key parameter of outstanding film and television works, and even become a key chip for films to win international film awards. Hong Kong Film Awards and other world famous film awards have set up the "best costume design" award, which highlights the significance of costume pattern design in film and television works. Taking Curse of the Golden Flower as an example, the film has made great efforts in costume pattern design, the low cut, the showy costume, the gold and silver armor and the imperial robe of the queen have caught the eyes of the audience, and achieved high ticket sales. Although the film did not win the Oscar statuette, the miraculous costume pattern design that awed the audience still won the best historical costume design award of the American Costume Designers Guild Awards. However, as the costume patterns of China's ancient-costume films yield unusually brilliant results, the following drawback gradually appears: the costume patterns become more and more beautiful and tend to steal the show, but the role shaping is pale and weak [1]. This requires a reunderstanding of the functions of role shaping in costume pattern design of ancient-costume films, and reasonable concepts and methods for costume pattern design should be found, so as to realize the unity of form and content of costume pattern design of ancient-costume films and give full play to the functions of role shaping.

\section{The functions of role shaping in costume pattern design of ancient-costume films}

Positioning of identity of characters. In ancient times, costume not only had the effect of covering up the embarrassment, keeping out the cold and beautifying, but also gave rise to the cultural connotations of social hierarchy division and advocating etiquettes and education, so that the identity of a person can be judged by costume [2]. In particular, with the development of productivity, the material, style and color of costume have been constantly enriched, the social hierarchy has been increasingly perfected, and thus costume has become an important symbol for division of social hierarchy and identification of identity. Therefore, the costume pattern design of ancient-costume films is closely related to the identity positioning of characters. For example, in the film The Banquet, Queen Wan was undoubtedly at the peak of power, hence, in order to highlight her authoritative and noble identity, her costume is exaggerated and gorgeous and manifests her 
traits of character of peremptoriness and overbearing, besides, the phoenix patterns on her sleeves and coat tail are exclusive to the queen, while for officials' children with far lower status and position than Queen Wan, the gorgeous degree of their costume colors, the splendid degree of their costume styles and the exaggerated degree of their costume decorative patterns are naturally far inferior to those of Queen Wan. The difference in costume pattern manifests the great disparity of identity. As for court maids with the lowest status in the film, the costume colors are simplex and less attentions are paid to details. Such differentiated treatment of costume pattern alleviates burdens on visual space and makes the audience more attentively focus on the protagonist, so as to clearly and concisely express the status and position of the roles and well set off the film's overall atmosphere by contrast.

In addition, in some ancient-costume films, the same character may have multiple identities, and these identities can often be distinguished by costume. For example, in the film The Promise, Qing Cheng portrayed by Cecilia Cheung was a down-and-out orphan whose mother died of an illness. She suffered from hunger and wars and wore a slop sewn up by burlap pieces, which foiled her emaciated body and abjection of living. However, after becoming the imperial concubine, Qing Cheng's identity and status greatly changed. Her clothes styles were complicated and the color was gorgeous, displaying flashy and noble dispositions. With the development of the plot, Qing Cheng descended to a prisoner of $\mathrm{Wu}$ Huan and was imprisoned in a huge birdcage, and her costume was changed into a long dress spliced by pure white feathers, which represented her identity of being in a pickle and regarded as an imprison bird or a plaything. The overall identity shift is positioned by different styles and colors of costumes. Therefore, costume can well describe the status and position of film roles, and quickly bring the audience into the scenes of the story.

Manifestation of character. In real life, different costume patterns can bring different feelings to people. Similarly, in the costume pattern design of ancient-costume films, the character traits can be expressed by costume pattern.

For example, Yu Jiaolong in the film Crouching Tiger, Hidden Dragon presented to the audience a free state without the secular burden of adults. Therefore, Yu's character did not contain the traditional code of conduct, which was greatly different from the mature and stable character of Li Mubai and Yu Xiulian. Yu's character presented as different states with the change of character relations, and the costume also changed accordingly. As a princess to leave the boudoir in the Baylor mansion, Yu needed to get along with the elder, so she wore Cheongsam and behaved dignified and clever. When $\mathrm{Yu}$ stole the green night sword and fought with $\mathrm{Yu}$ Xiulian in the twilight, Yu wore black nocturnal clothing and behaved arrogant and unruly. When encountered robbers and engaged in a life-and-death struggle, Yu wore bright-colored long coat and trousers and behaved brave and tenacious. When lingering with Luo Xiaohu in the cave, Yu wore loose men's clothing with exposed navel and thighs and behaved unrestrained and fervent. It is just because of the changeable character of $\mathrm{Yu}$, the role has the most changes of clothing colors and styles in the film.

For another example, blue-eyed fox is a role in Crouching Tiger, Hidden Dragon who did years of evil and hid in the Yu mansion. She wore gown and pants and wore her hair in a high bun, being neat and tidy. Her costume had no bright color and can be simplified as an unimpressive black color lump. This is just the embodiment of the crafty and camouflaged character of the blue-eyed fox. When fighting with Li Mubai, blue-eyed fox wore black clothing made from thick cloth and with unbounded style, which is an embodiment of the burst of her hidden character and her originally insolent, overbearing and mad character [3].

As to $\mathrm{Yu}$ Xiulian, she was calm, restrained, forbearing and sensible in the film, her costume pattern design started from colors, that is, as long as she is in the frame, the clothing color of the person who plays opposite darkens, and fresh sandal wood color, cream color or light purple or other neutral colors are applied to her, thus highlighting her role charm of naive heroine [4].

Conveying of character emotions. The emotional expression of film characters is also an important function of film costume pattern. The conveying of psychological activities, emotional reactions, emotional states and other activities of the film roles is often realized through the shift of 
costume colors, the adjustment of styles and the change of hairstyle. In Crouching Tiger, Hidden Dragon, Yu Jiaolong was traitorous, wild, rebellious, freewheeling, stubborn and self-willed, accordingly, her costume was complicated and gorgeous, which foiled her instable psychological status of being vulnerable to provocation to burst the lust of conquest. When appeared on the screen for the last time, Yu Jiaolong wore plainly and simply: a dark grey front opening cardigan, a long milk-white right lapel gown and long pale brown wide leg pants, the overall outline is loose-bodied and terse, without any superfluous decoration. As Yu was humanized by Li Mubai after the martial arts competition, she was deeply sorry for the death of Li Mubai, her aggressive, emulative, arrogant and capricious psychological status was calmed, she became indifferent, hated the mortal life and pursued internal peace, so as to redeem her once made mistake, finally, she jumped off the cliff and ended her life.

Implying of characters' fates. In films, the ups and downs of the fates of the characters will attract more attention of the audience, and the firm and tenacious character of being superior to hardships and struggling with the fate of the roles will promote the development of the film plot. The above process can not be separated from the vital function of costume pattern, as costume can imply the situation and fate of the characters, and promote film progress together with plot[5].

In The Banquet, at first Queen Wan wore white mourning apparel with floor-length backswing and walked forward slowly. Her husband had a sudden death, her uncle usurped the throne, and the prince was on the verge of death or destruction. At this moment, the fate was capricious and beyond control and Queen Wan felt pale and weak. For the sake of the prince's safety, Queen Wan voluntarily married Emperor Li, her fate was no longer like duckweed and uncertain, instead, she became the queen who preceded all men except the king. At this time, she wore a dark brown suit and held the alizarin red cloth prepared for the coronation ceremony on hand, the dark brown and the bright red formed a strong visual impact, the queen's words and expressions showed her elation of crowning once again, and her ambition was also revealed somewhat. At the moment, Queen Wan mastered her fate and reached the peak of her life. She was dressed in an alizarin red tailing long gown with flying phoenix and wore gold ornaments. She walked slowly into the great hall, the scene was similar to that in which she wore white mourning apparel, but her fate was reversed. The smooth road that symbolized power, dignity and glory and splendor was presented in front of Queen Wan. Finally, she removed all her political opponents and made the ascent of the peak of power. However, she in brown suit was unable to resist the sad fate, and she eventually died from a stab in the back in front of the fishpond.

\section{Costume pattern design methods based on the requirements of role shaping in ancient- costume films}

It can be seen from the above analysis that it is inevitable for an excellent ancient-costume film to shape roles through costume pattern design, but the function of role shaping in ancient-costume films manifested by costume pattern design is various and abundant, which cannot be completely abandoned or covers all the bases. This requires the grasp of certain design philosophies and methods in costume pattern practices, namely, the costume pattern design based on the requirements of role shaping in ancient-costume films.

In the process of costume pattern design in ancient-costume films, the positioning of various film roles can be analyzed in accordance with the needs of the script, including the roles' identity, status, disposition and psychological process. Only when the costume pattern design is conducted based on the image characteristics of the roles, will the design conform to the story line and meet the requirements of role shaping. In order to successfully create costume patterns that live up to the film roles, the first thing to do is to study the script, make clear the historical background of the story, achieve an in-depth understanding of the identity, status and disposition of the roles as well as the development and change of the character images. Besides, the self-quality of the actors should be taken as the prerequisite to determine the style of the costume pattern. Afterwards, an intensive study of the historical background of the ancient-costume film roles and the then costume characteristics should be made, and the costume characteristics should be thoroughly grasped from 
multiple macroscopic perspectives of era, territory and nationality. Based on complete historical data, each role's age, occupation, identity and disposition should be analyzed, and an explicit thought for each role should be proposed. Furthermore, the development and changing process of each role should be staged in details, so as to carry out costume pattern design according to different roles and image development periods. In the above process, attention should be paid to the overall grasp of the costume pattern styles, thus distinguishing the leading roles from the supporting roles and distinguishing the visible clues from the invisible ones, so as to reinforce the theme [6]. However, the costumes of these roles should have a global style positioning, lest the audience have a visual inharmonious feeling. Finally, the three elements of costume styles, colors and fabrics should be made rational use of, as the costume styles and fabrics can directly reflect the social status, psychological changes and character traits of the roles, and costume color is the most direct expression of inner emotions of the roles. Only when these three elements are rationally used, will the costume in conformity with the requirements of role shaping in ancient-costume films be worked out.

\section{Conclusions}

The costume pattern design in ancient-costume films is not the simple combination of elements and the application of methods, but closely related to the designer's life experience, artistic appreciation and artistic creativity. This requires the grasp of design, photography, performance and other related knowledge in the process of costume pattern design. In addition to this, scrupulous observation ability, profound appreciation and overall control capacity are needed, thus laying the foundation for costume pattern design of excellent ancient-costume films.

\section{Acknowledgement}

Jiangsu Open University: "13th Five-Year Plan" scientific research project (No. 16SSW-Y-011): "Study achievements of costume pattern and role shaping in Chinese ancient-costume films and television programs.

In this paper, the research was sponsored by the Nature Science Foundation of Henan Province (Project No. 201112400450401) and Youth Fund Project of Luoyang Institute of Science and Technology (Project No. 2010QZ16).

\section{References}

[1] Wu Ying. Spectacle, imagination and sexual characterization-discussion on costume patterns in Chinese contemporary film and television works [D]. Zhejiang University, 2011.

[2] Hua Mei. Costume and Chinese culture [M]. Beijing: People's Publishing House, 2001.

[3] Li Rui. Preliminary assessment on the artistic design style of Crouching Tiger, Hidden Dragon [J]. Film Literature, 2011 (21): 129-130.

[4] Ye Jingtian. A study of the female costume art in ancient-costume films [D]. Southwest University, 2016.

[5] Li Yun. Features and implication interpretation of costume patterns in Chinese contemporary magical fantasy and martial-arts films [D]. Qufu Normal University, 2012.

[6] Xu Haiqin. A study of the symbolic ideographic function of costume language of film characters [D]. Shandong Normal University, 2009. 